\title{
Intravescical prostatic protrusion is a predictor of alpha blockers response: results from an observational study
}

\author{
L. Topazio ${ }^{1 *}$, C. Perugia' ${ }^{1}$, C. De Nunzio², G. Gaziev ${ }^{1}$, V. lacovelli ${ }^{1}$, D. Bianchi ${ }^{1}$, G. Vespasiani ${ }^{3}$ and E. Finazzi Agrò ${ }^{3}$
}

\begin{abstract}
Background: To investigate the efficacy of tamsulosin in patients with lower urinary tract symptoms (LUTS) and benign prostatic enlargement (BPE) with intravesical prostatic protrusion (IPP). Ultrasound measurement of the IPP has been previously described as an effective instrument for the evaluation of benign prostatic obstruction (BPO) and could help in clarifying the role of alpha-blockers in patients with (BPE).

Methods: Patients with BPE and LUTS were enrolled in this observational study. Intravesical prostatic protrusion was graded as grade $1(<5 \mathrm{ml}), 2(5<\mathrm{IPP}<10 \mathrm{ml})$ and $3(>10 \mathrm{ml})$. Patients were treated with tamsulosin for twelve weeks. Evaluation was performed before and at the end of treatment by means of International Prostate Symptom Score (IPSS) and uroflowmetry. Patients were considered responders if a reduction of IPSS > 3 points was reported.

Results: One hundred forty-two patients were enrolled. Twelve patients were excluded because of incomplete data. Fifty patients showed an IPP grade 1 (group A), 52 a grade 2 (group B) and 28 a grade 3 (group C). Treatment success was obtained in $82 \%, 38,5 \%$ and $7,1 \%$ of patients respectively; these differences (group A vs B-C and group $B$ vs C) were highly significant. The odd ratio to obtain a treatment success was of 59 and 8.1 in group $A$ and group B respectively, in comparison to group C. After a multivariate regression, the relationship between IPP grade and treatment success remained significant. Improvement of uroflowmetry parameters has been reported in all the groups especially in patients with a low grade IPP ( $p$ value $=0,016$ group A vs group $B ; p$ value $=0,005$ group A vs group C). Prostate volume seems not to influence this relationship.

Conclusions: Intravesical prostatic protrusion has found to be significantly and inversely correlated with treatment success in patients with LUTS and BPE under alpha-blockers therapy. Alpha blockers odd ratio of success is 59 times higher in patients with a low grade IPP in comparison to patients with a high grade.
\end{abstract}

Keywords: LUTS, BPH, Alpha-blockers, Intravesical prostatic protrusion

\section{Background}

Benign prostatic hyperplasia $(\mathrm{BPH})$ is found in over half of 60-year-old men and in almost all of 80-year-old men [1] and is the most frequent cause of bladder outlet obstruction (BOO) in males over the age of 50 who apply with lower urinary tract symptoms [2]. In this case, the term Benign Prostatic Obstruction (BPO) is currently used [3]. In BPO patients, medical therapy is the most commonly used [3] and provides relief in symptoms and alteration in disease progression [4]. However, long-term

\footnotetext{
* Correspondence: lucatpz@hotmail.it

'School of Specialization in Urology, University "Tor Vergata", Rome, Italy Full list of author information is available at the end of the article
}

dropout rates reach $30-43 \%$ [5] and not all patients benefit from the treatment. Therefore, it would be beneficial to identify patients that will not respond to medical treatment.

The evaluation of BPO is an important factor that can reflect the severity of disease and can aid in measuring the outcome of the treatment. Nowadays the standard practice investigation for $\mathrm{BPO}$ patients is composed of uroflowmetry and ultrasound (US) evaluation of the post-void residual urine (PVR) [3]. Unfortunately, such investigations have less possibility to clearly identify the degree of $\mathrm{BOO}$ in men affected by Benign prostatic enlargement (BPE) with respect to pressure-flow study 
(PFS) during invasive urodynamic investigation (UD) [6]. However, UD test before surgical BPO treatment is not always indicated in international guidelines because of the invasiveness and high costs of the method [3, 7].

In the last decade, several authors have tried to identify novel and less invasive parameters that could help the physician in evaluating the degree of BPO, thus predicting a treatment response. The most promising among them are bladder/detrusor wall thickness $[8,9]$, ultrasound-estimated bladder weight [10], non-invasive pressure-flow testing [11], prostatic urethral angle [12] and US measurement of the intravesical prostatic protrusion (IPP) $[11,13,14]$.

US measurement of IPP was first described by Chia et al. in 2003 to correlate well with BPO (presence and severity) on urodynamic testing, with a PPV of $94 \%$ and a NPV of 79\% [13]. The clinical significance of IPP can be explained by the fact that protrusion of the median lobe of the prostate into the bladder can cause a "ball valve" type of benign prostatic obstruction with incomplete opening and disruption of the funneling effect of the bladder neck [13, 15].

Further studies on this topic have shown that IPP may correlate with prostate volume, detrusor overactivity (DO), bladder compliance, detrusor pressure at maximum urinary flow, BOO index and PVR, and negatively correlates with Qmax [16]. Moreover, IPP also seems to predict successfully the outcome of a trial without catheter (TWOC) after acute urinary retention [17] and the success rate of TURP [18]. To date, however, few data have been reported in terms of the association between IPP and clinical outcomes in patients undergoing medical therapy. Studies investigating the relationship between IPP and alpha-blockers therapy outcomes [19, 20] have shown that it may be correlated to reduced efficacy of alpha blockers in patients with IPP and mild/moderate $(<40 \mathrm{ml})$ prostate volume (PV) $[19,20]$. However, to our knowledge, no data are available on patients with $\mathrm{PV} \geq 40 \mathrm{ml}$.

Aim of this study was to investigate the efficacy of an alpha-blocker (Tamsulosin) in patients with lower urinary tract symptoms (LUTS) and BPE with or without IPP.

\section{Methods}

This is an observational prospective study performed from January to December 2015 in the outpatient clinic of Tor Vergata University Hospital in Rome and reported following the STROBE statement.

We enrolled male patients between fifty and seventyfive years of age, affected by BPE defined as trans-rectal ultrasound (TRUS) estimated PV $\geq 30 \mathrm{ml}$, in whom tamsulosin had been prescribed for LUTS.
Exclusion criteria were:

- Prior urologic surgery;

- Patients affected by a urologic neoplasia, bladder calculus or any type of neurological abnormality;

- Prior treatment with alpha blockers and 5alpha reductase inhibitors;

- Absence of intravescical prostatic protusion.

All patients enrolled underwent a baseline evaluation by means of medical history, administration of the International Prostate Symptom Score and Quality of Life (IPSS/QoL) questionnaire, trans-rectal ultrasound of the prostate and uroflowmetry. All TRUS were performed by the same physician and at the standard bladder filling of $150 \mathrm{ml}$. Trans rectal ultrasound was performed in the midsagittal plane and IPP along with the prostatic volume were measured. IPP was identified according to the classification system used by Nose et al [21] and was defined by the distance from the tip of the prostate's protrusion into the vesical lumen to the bladder neck measured in millimetres. IPP estimated by TRUS was then graded as Grade 1 (if it was inferior to $5 \mathrm{~mm}$ ), Grade 2 (if it was comprised between 5 and $10 \mathrm{~mm}$ ) and Grade 3 (if it was superior to $10 \mathrm{~mm}$ ). PV measurement was obtained during TRUS. All uroflowmetry were performed at the standard bladder filling of $250-300 \mathrm{ml}$ as recommended by the guidelines for good urodynamic practices [22].

All patients enrolled were then treated with Tamsulo$\sin (0,4 \mathrm{mg} /$ day $)$ for twelve weeks and re-evaluated after treatment by means of International Prostate Symptom Score and Quality of Life (IPSS/QoL) and uroflowmetry. Patients were considered responders (treatment success) if showing a reduction of IPSS $>3$ points.

\section{Statistical analysis}

All data were classified in an Excel Database. All analyses were performed by means of the software STATA 13.0. Univariate logistic regression was used to evaluate relationships between each parameter (IPP grade, PV, IPSS, Qmax, PSA) and treatment success. A paired t test was used to evaluate change in time in uroflow parameters in each group separately. One way anova was used to compared these changes between the three groups. Bonferroni correction was applied in post hoc comparison. Univariable logistic regression was used to evaluate relationships between IPP grade and the treatment success. Odd Ratio (OR) and relative 95\% confidence Interval (CI 95\%) were reported. A stepwise logistic regression was applied considering as independent factor IPP grade, age PSA, PV and baseline value of Qmax IPSS and RPM. Adjusted OR (ORadj) and relative 95\% confidence Interval (CI 95\%) were reported. A $p$ value $<0.05$ was considered statistically significant. 
Table 1 Baseline features of Patients

\begin{tabular}{lllllll}
\hline & $\begin{array}{l}\text { Age, } \\
\text { mean (DS) }\end{array}$ & $\begin{array}{l}\text { Prostate volume, } \\
\text { mean (DS) }\end{array}$ & $\begin{array}{l}\text { Estimated IPP, } \\
\text { mean (DS) }\end{array}$ & $\begin{array}{l}\text { Pre-treatment Qmax, } \\
\text { mean (DS) }\end{array}$ & $\begin{array}{l}\text { Pre-treatment IPSS, } \\
\text { mean (DS) }\end{array}$ & $\begin{array}{l}\text { Pre-treatment PSA, } \\
\text { mean (DS) }\end{array}$ \\
\hline Group A & $62(8.9)$ & $45.5(16.9)$ & $2.7(0.8)$ & $10.5(2.9)$ & $17.7(3.9)$ & $3.5(2.5)$ \\
Group B & $64(9)$ & $53.2(21.2)$ & $6.5(1.3)$ & $9.3(1.5)$ & $18(4.1)$ & $2(1.4)$ \\
Group C & $66(8.6)$ & $54.6(13.1)$ & $11.4(1.1)$ & $8.8(2.3)$ & $22.2(5.1)$ & $3.1(1.7)$ \\
\hline
\end{tabular}

IPP Intravesical prostatic protrusion, Qmax Maximum flow at uroflowmetry, IPSS International prostatic symptoms score

\section{Results}

One hundred forty-two patients were enrolled. Twelve patients were excluded because of incomplete data. Of the remaining 130 patients, $50(38.5 \%)$ showed an IPP grade 1 (group A), 52 (40\%) an IPP grade 2 (group B) and $28(21.5 \%)$ an IPP grade 3 (group C). Baseline features of patients are showed in Table 1. Treatment success, defined as post-treatment IPSS score reduction $>3$ points, was obtained in $82 \%, 38,5 \%$ and $7,1 \%$ of patients respectively. The odd ratio to obtain a treatment success was of 59 (CI 95\% 11.8-296) and 8.1 (CI95\% $1.7-38$ ) in group A and group B respectively, in comparison to group $\mathrm{C}$ (Table 2). Moreover, there is a positive improvement of uroflow parameters in each group (Table 3) with a better improvement after treatment in patients with a low grade IPP with respect to patients with a higher grade IPP ( $p$ value $=0,016$ Group A vs Group B; $p$ value $=0,005$ Group A vs Group C).

After multivariate regression, the relationship between IPP grade and treatment success remained significant. Interestingly the multivariate regression shows that PV seems not influence this relationship and is not included in the final model (Table 4).

\section{Discussion}

IPP is a promising parameter, first described by Chia in 200,313 , that has shown a good correlation with the presence and severity of BPO on urodynamic testing. Further studies have found a strong correlation between IPP and DO, bladder compliance, detrusor pressure at maximum urinary flow, terminal dribbling, BOO index and PVR while a negative correlation was found between IPP and Qmax and/or alpha-blockers efficacy $[16,19,20,23]$. Moreover a well-designed study from Luo GC et al. has shown that the presence of middle lobe is more obstructive than those of lateral lobes and could better correlate with BOO grade [24]. Data

Table 2 Relationship between IPP grade and treatment success

\begin{tabular}{llllll}
\hline & Responders & Not responders & OR & Cl 95\% & $p$ \\
\hline Group A & $41(65.1 \%)$ & $9(13.4 \%)$ & 59 & $11.8-296$ & $<0.001$ \\
Group B & $20(31.7 \%)$ & $32(47.8 \%)$ & 8.1 & $1.7-38$ & 0.008 \\
Group C & $2(3.2 \%)$ & $26(38.8 \%)$ & 1 & & \\
\hline
\end{tabular}

OR Odd ratio, $\mathrm{Cl}$ Confidence interval coming from our study suggest that IPP is significantly and inversely correlated with treatment success in patients affected by BPE and with LUTS under alpha-blocker therapy. Alpha-blockers odd ratio of success is 59 times higher in patients with a low grade IPP in comparison to patients with a high grade IPP and 8 times higher with respect to patients with a moderate grade IPP. It is important to underline that the definition of success used in this study (a reduction of IPSS score $>3$ points) is in line with previous and contemporary studies, considering this IPSS variation as clinically significant [25]. Interestingly even after multivariate regression with stepwise logistic regression IPP remains as independent predictive factors for alpha blockers treatment success.

Our data are similar to those in literature; Cumpanas et al. analyzed 183 patients with $\mathrm{BPH}(\mathrm{PV}<40 \mathrm{~mL})$ treated with tamsulosin and found that approximately $40 \%$ of the patients in the high IPP group were treatment nonresponders and had significantly worse outcomes than patients in the low IPP group at 3 months [20]; even in a more recent paper Kalkanli et al. [26] showed that an increase in IPP was associated with a lower response level to medical treatment and indicated a significant negative correlation between IPP-Qmax and IPP-post treatmens IPSS. Similar data were also published by Hirayama et al [27] in Patients treated with Dutasteride $0.5 \mathrm{mg}$ daily in which IPP was seen to be the strongest predictive factor for failure of medical therapy and conversion to surgical intervention with the optimal cutoff value of IPP of $8 \mathrm{~mm}$. This value yielded a sensitivity of $91 \%$ and a specificity of $72 \%$.

Interestingly our data show that PV seems not to influence the relationship between IPP and alpha-blockers success rate. This is, to our knowledge, one of the very first papers to investigate this relationship in Patients with PV higher than $40 \mathrm{ml}$ and our results are similar to those already published by Wang et al. in 2015 [28] who showed a strong correlation between IPP and BPO and stated that IPP is superior to PV in predicting BPO in patients who present with LUTS.

Our result indicates that IPP helps to predict obstruction by $\mathrm{BPH}$ and therefore the progression of $\mathrm{BPH}$ (prostate adenoma) and response rate to alpha blockers therapy; therefore, IPP is useful in stratifying BPH patients with LUTS at initial evaluation, helping the urologist in 
Table 3 Pre post-treatment Qmax differences

\begin{tabular}{lllll}
\hline & $\begin{array}{l}\text { Pre-treatment Qmax, } \\
\text { mean (SD) }\end{array}$ & $\begin{array}{l}\text { Post-treatment Qmax, } \\
\text { mean (SD) }\end{array}$ & $\begin{array}{l}\text { Pre post-treatment Qmax } \\
\text { differences, mean (SD) }\end{array}$ & pValue \\
\hline Group A & $10.5(2.9)$ & $14.1(3.2)$ & $3.6(1.4)$ & $<0.001$ \\
Group B & $9.3(1.5)$ & $11.7(2.7)$ & $2.4(2.7)$ & $<0.001$ \\
Group C & $8.8(2.3)$ & $10.8(2.7)$ & $2.0(2.2)$ & $<0.001$ \\
\hline
\end{tabular}

Qmax Maximum flow at uroflowmetry

deciding which patient could benefit from medical therapy and avoiding lots of unuseful prescriptions for further cost-effective management.

It is interesting to observe that also Qmax showed a larger improvement in low or moderate IPP grade patients in comparison to severe IPP grade patients ( $p$ value $=0,016$ Group A-B vs Group C). Furthermore, patients with a higher IPP grade showed lower pre-treatment Qmax, in comparison with patients with 1-2 IPP grade ( $p$ value $=0,029$ Group A-B vs Group $C$ ). This finding seems to suggest that the degree of IPP could correlate with the degree of BPO, but the lack of an invasive urodynamic evaluation (pressure/flow study) do not allow us to draw conclusions on that point.

The study has several limitations; no RCT, no sample size calculation; non-invasive UD data. Besides we are conscious that EAU Guidelines on "Non neurogenic male LUTS" [3] suggest a combination therapy for patients with $\mathrm{PV}>40 \mathrm{ml}$ and therefore that the vast majority of patients in our study did not receive a Guideline conform therapy but the aim of this study was not to evaluate the efficay of tamsulosin monotherapy in PV > $40 \mathrm{ml}$ but to assess the efficacy of alpha-blockers in relationship to the IPP grade. Thus the results of this paper could reinforce the indication of a combination therapy in this patients' population. This study provides furthermore the information that IPP seems to be a negative prognosctic factor for success of Tamsulosin, independently by the prostate volume.

The strengths of the study are a proper statistical methodology and the use of a clinically meaningful primary outcome measure as modifications in IPSS score.

Table 4 Multivariate regression on treatment success

\begin{tabular}{|c|c|c|c|c|}
\hline & ORadj & $\mathrm{Cl} 95 \%$ & & $P$ value \\
\hline \multicolumn{5}{|l|}{ IPP grade } \\
\hline Grade 1 & 84.83 & 14.31 & 502.93 & $<0.001$ \\
\hline Grade 2 & 8.70 & 1.70 & 44.51 & 0.009 \\
\hline Grade 3 & 1 & & & \\
\hline Age & .95 & .90 & 1.00 & 0.071 \\
\hline PSA & .74 & .58 & .94 & 0.014 \\
\hline PVR pre & .99 & .97 & .99 & 0.037 \\
\hline
\end{tabular}

Stepwise regression. Initial model: IPP grade, PSA, PV, Qmax baseline, IPSS baseline, RPM baseline

\section{Conclusions}

IPP seems significantly and inversely correlated with treatment success in patients with LUTS and BPE under alpha-blockers and may be considered a useful tool to discriminate patients in whom medical treatment has higher (low grade IPP) or lower (high grade IPP) probability of success.

\section{Abbreviations}

BOO: Bladder outlet obstruction; BPE: Benign prostatic enlargement; $\mathrm{BPH}$ : Benign prostatic hyperplasia; BPO: Benign Prostatic Obstruction; Cl: Confidence interval; DO: Detrusor overactivity; IPP: Intravesical prostatic protrusion; IPSS/QoL: International Prostate Symptom Score and Quality of Life; LUTS: Lower urinary tract symptoms; OR: Odd Ratio; PFS: Pressure-flow study; PV: Prostate volume; PVR: Post-void residual urine; TRUS: Trans-rectal ultrasound; TWOC: Trial without catheter; UD: Urodynamic investigation; US: Ultrasound

\section{Acknowledgements \\ None \\ Funding \\ None}

Availability of data and materials

The datasets used and/or analysed during the current study are available from the corresponding author on reasonable request.

\section{Authors' contributions}

LT has participated in data analysis and interpretation and drafting the article; CP, VI and GG have participated in data collection; DB, CDN and VG have participated in critical revision of the article; EFA have participated in conception and design of the work. All authors have given final approval of the version to be published.

\section{Ethics approval and consent to participate}

Observational study. Informed consent was obtained from the patients' and authorization was obtained from our IRB - Policlinico Tor Vergata Ethics

Committee for data collection and publication.

Consent for publication

Not applicable.

Competing interests

The authors declare that they have no competing interests

\section{Publisher's Note}

Springer Nature remains neutral with regard to jurisdictional claims in published maps and institutional affiliations.

\section{Author details}

"School of Specialization in Urology, University "Tor Vergata", Rome, Italy. ¿Department of Urology, Sant'Andrea Hospital, University "La Sapienza", Rome, Italy. ${ }^{3}$ Department of Experimental Medicine and Surgery, University "Tor Vergata", Rome, Italy. 
Received: 23 February 2017 Accepted: 24 January 2018 Published online: 02 February 2018

\section{References}

1. Platz EA, Smit E, Curhan GC, Nyberg LM, Giovannucci E. Prevalence of and racial/ethnic variation in lower urinary tract symptoms and noncancer prostate surgery in U.S. men. Urology. 2002;59:877-83.

2. Martin SA, Haren MT, Marshall VR, et al. Prevalence and factors associated with uncomplicated storage and voiding lower urinary tract symptoms in community-dwelling Australian men. World J Urol. 2011;29:179-84.

3. EAU guidelines on Management of Non-Neurogenic Male Lower Urinary Tract Symptoms (LUTS), incl. Benign Prostatic Obstruction (BPO)S. Gravas (Chair), T. Bach, A. Bachmann, M. Drake, M. Gacci, C. Gratzke, S. Madersbacher, C. Mamoulakis, K.A.O. Tikkinen Guidelines Associates: M. Karavitakis, S. Malde, V. Sakkalis, R. Umbach. LIMITED UPDATE MARCH 2016.

4. Mc Connell JD, Roehrborn CG, Bautista OM, et al. The long-term effect of doxazosin, finasteride, a combination therapy on the clinical progression of benign prostatic hyperplasia. N Engl J Med. 2003;349:2387-98.

5. Lepor $\mathrm{H}$. Long term efficacy and safety of terazosin in patients with benign prostatic hyperplasia. The terazosin research group. Urology. 1995;45:406-13.

6. Nitti WW, Kim Y, Combs AJ. Correlation of the AUA symptom index with urodynamics in patients with suspected benign prostatic hyperplasia. Neurourol Urodyn. 1994;13(5):521-7. discussion 527-9

7. van Venrooij GE, van Melick HH, Boon TA. Comparison of outcomes of transurethral prostate resection in urodynamically obstructed versus selected urodynamically unobstructed or equivocal men. Urology. 2003;62: 672-6.

8. Oelke $\mathrm{M}$, et al. Diagnostic accuracy of noninvasive tests to evaluate bladder outlet obstruction in men: detrusor wall thickness, uroflowmetry, postvoid residual urine, and prostate volume. Eur Urol. 2007;52:827.

9. Blatt $\mathrm{AH}$, et al. Ultrasound measurement of bladder wall thickness in the assessment of voiding dysfunction. J Urol. 2008;179:2275.

10. Kojima $\mathrm{M}$, et al. Ultrasonic estimation of bladder weight as a measure of bladder hypertrophy in men with infravesical obstruction: a preliminary report. Urology. 1996:47:942.

11. Pel JJ, et al. Development of a non-invasive strategy to classify bladder outlet obstruction in male patients with LUTS. Neurourol Urodyn. 2002;21:117.

12. Park $Y J$, Bae $K H$, Jin BS, Jung HJ, Park JS. Is increased prostatic urethral angle related to lower urinary tract symptoms in males with benignprostatic hyperplasia/lower urinary tract symptoms? Korean J Urol. 2012 Jun;53(6): 410-3. doi:10.4111/kju.2012.53.6.410. Epub 2012 Jun 19

13. Chia SJ, et al. Correlation of intravesical prostatic protrusion with bladder outlet obstruction. BJU Int. 2003;91:371-4.

14. Kessler TM, et al. Ultrasound assessment of detrusor thickness in men-can it predict bladder outlet obstruction and replace pressure flow study? J Urol. 2006;175:2170.

15. Zheng J, Pan J, Qin Y, Huang J, Luo Y, Gao X, Zhou X. Role for intravesical prostatic protrusion in lower urinary tract symptom: a fluid structural interaction analysis study. BMC Urol. 2015 Aug 19;15:86 doi:10.1186/s12894-015-0081-y.

16. Keqin $Z$, et al. Clinical significance of intravesical prostatic protrusion in patients with benign prostatic enlargement. Urology. 2007;70:1096.

17. Mariappan $\mathrm{P}$, et al. Intravesical prostatic protrusion is better than prostate volume in predicting the outcome of trial without catheter in white men presenting with acute urinary retention: a prospective clinical study. J Urol. 2007;178:573.

18. Lee JW, Ryu JH, Yoo TK, Byun SS, Jeong YJ, Jung TY. Relationship between Intravesical prostatic protrusion and postoperative outcomes in patients with benign prostatic hyperplasia. Korean J Urol. 2012 Jul;53(7):478-482. doi:10.4111/kju.2012.53.7.478. Epub 2012 Jul 19.

19. Park HY, Lee JY, Park SY, Lee SW, Kim YT, Choi HY, Moon HS. Efficacy of alpha blocker treatment according to the degree of intravesical prostatic protrusion detected by transrectal ultrasonography in patients with benign prostatic hyperplasia. Korean J Urol 2012 Feb;53(2):92-97. doi:10.4111/kju.2012.53.2.92. Epub 2012 Feb 20.

20. Cumpanas AA, Botoca M, Minciu R, Bucuras V. Intravesical prostatic protrusion can be a predicting factor for the treatment outcome in patients with lower urinary tract symptoms due to benign prostatic obstruction treated with tamsulosin. Urology 2013 Apr; 81(4):859-863. doi:10.1016/j.urology.2012.12.007. Epub 2013 Jan 30.
21. Nose H, Foo KT, Lim KB, Yokoyama T, Ozawa H, Kumon H. Accuracy of two noninvasive methods of diagnosing bladder outlet obstruction using ultrasonography: intravesical prostatic protrusion and velocity-flow video urodynamics. Urology. 2005;65:493-7.

22. Werner Schafer, ${ }^{*}$ Paul Abrams, Limin Liao, Anders Mattiasson, Francesco Pesce, Anders Spangberg, Arthur M. Sterling, Norman R. Zinner, and Philip van Kerrebroeck Good urodynamic practices: Uroflowmetry, filling Cystometry, and pressure-flow studies. Neurourol Urodyn 2002;21:261-274.

23. Kim JH, Shim JS, Choi H, Moon du G, Lee JG, Kim JJ, Bae JH, Park JY. Terminal dribbling in male patients with lower urinary tract symptoms: relationship with international prostate symptom score and with intravesical prostatic protrusion. BMC Urol. 2015 Aug 29;15:89. doi:10.1186/s12894-015-0082-x.

24. Luo GC, Foo KT, Kuo T, Tan G. Diagnosis of prostate adenoma and the relationship between the site of prostate adenoma and bladder outlet obstruction. Singap Med J. 2013 Sep;54(9):482-6.

25. Barry MJ, Williford WO, Chang Y. Benign prostatic hyperplasia specific health status measures in clinical research: how much change in the American urological association symptom index and the benign prostatic hyperplasia impact index is perceptible to patients? J Urol. 1995;154:1770-4.

26. Kalkanli A, Tandogdu Z, Aydin M, Karaca AS, Hazar Al, Balci MBC, Aydin M, Nuhoglu B. Intravesical prostatic protrusion:a potential marker of alphablocker treatment success in patients with benign prostatic enlargement. Urology. 2016;88:161-5.

27. Hirayama K, Masui K, Hamada A, Shichiri Y, Masuzawa N, Hamada S. Evaluation of Intravesical prostatic protrusion as a predictor of Dutasterideresistant lower urinary TractSymptoms/benign prostatic enlargement with a high likelihood of surgical intervention. Urology. 2015;86:565-9.

28. Wang D, Huang H, Law YM, Foo KT. Relationships between prostatic volume and Intravesical prostatic protrusion on transabdominal ultrasound and benign prostatic obstruction in patients with lower urinary tract symptoms. Ann Acad Med Singap. 2015;44:60-5.

\section{Submit your next manuscript to BioMed Central and we will help you at every step:}

- We accept pre-submission inquiries

- Our selector tool helps you to find the most relevant journal

- We provide round the clock customer support

- Convenient online submission

- Thorough peer review

- Inclusion in PubMed and all major indexing services

- Maximum visibility for your research

Submit your manuscript at www.biomedcentral.com/submit
Biomed Central 